\title{
Genetic Differentiation of Verticillium dahliae Populations Recovered from Symptomatic and Asymptomatic Hosts
}

\author{
Laura S. Bautista-Jalón, ${ }^{1}$ Omer Frenkel, ${ }^{2}$ Leah Tsror (Lahkim), ${ }^{3}$ Glenna M. Malcolm, ${ }^{4}$ Beth K. Gugino, ${ }^{1}$ Sara Lebiush, ${ }^{4}$ \\ Marina Hazanovsky, ${ }^{4}$ Michael G. Milgroom, ${ }^{5}$ and María del Mar Jiménez-Gasco ${ }^{1, \dagger}$ \\ ${ }^{1}$ Department of Plant Pathology and Environmental Microbiology, The Pennsylvania State University, University Park, PA 16802, U.S.A. \\ ${ }^{2}$ Department of Plant Pathology and Weed Research, Volcani Center, Rishon Lezion 7528809, Israel \\ ${ }^{3}$ Department of Plant Pathology and Weed Research, Gilat Center, M.P. Negev, 8531100, Israel \\ ${ }^{4}$ Department of Biology, The Pennsylvania State University, University Park, PA 16802, U.S.A. \\ ${ }^{5}$ School of Integrative Plant Science, Plant Pathology and Plant-Microbe Biology Section, Cornell University, Ithaca, NY 14853, U.S.A. \\ Accepted for publication 15 October 2020.
}

\begin{abstract}
Verticillium dahliae is a soilborne fungal pathogen affecting many economically important crops that can also infect weeds and rotational crops with no apparent disease symptoms. The main research goal was to test the hypothesis that $V$. dahliae populations recovered from asymptomatic rotational crops and weed species are evolutionarily and genetically distinct from symptomatic hosts. We collected V. dahliae isolates from symptomatic and asymptomatic hosts growing in fields with histories of Verticillium wilt of potato in Israel and Pennsylvania (United States), and used genotyping-by-sequencing to analyze the evolutionary history and genetic differentiation between populations of different hosts. A phylogeny inferred from 26,934 single-nucleotide polymorphisms

The lineages identified in this study were differentiated by host of origin; we found $2 \mathrm{~A}, 2 \mathrm{~B}^{824}$, and $4 \mathrm{~A}$ only in symptomatic hosts but isolates from asymptomatic hosts (weeds, oat, and sorghum) grouped exclusively within lineage 4B, and were genetically indistinguishable from 4B isolates sampled from symptomatic hosts (potato, eggplant, and avocado). Using coalescent analysis of 158 SNPs of lineage 4B, we inferred a genealogy with clades that correlated with geographic origin. In contrast, isolates from asymptomatic and symptomatic hosts shared some of the same haplotypes and were not differentiated. We conclude that asymptomatic weeds and rotational hosts may be potential reservoirs for $V$. dahliae populations of lineage $4 \mathrm{~B}$, which are pathogenic to many cultivated hosts.
\end{abstract} (SNPs) in $126 \mathrm{~V}$. dahliae isolates displayed a highly clonal structure correlated with vegetative compatibility groups, and isolates grouped in lineages $2 \mathrm{~A}, 2 \mathrm{~B}^{824}, 4 \mathrm{~A}$, and $4 \mathrm{~B}$, with $77 \%$ of the isolates in lineage $4 \mathrm{~B}$.
Keywords: ecology, epidemiology, fungal pathogens, genomics, population biology
Plant-pathogenic microorganisms have a range of interactions with their hosts other than those that result in disease. Microbial species traditionally considered to be plant pathogens have been found interacting with plant hosts as endophytes without causing apparent disease (Bacon and Hinton 1996; Lofgren et al. 2018; Malcolm et al. 2013), living on plant surfaces as epiphytes (Xin et al. 2018), colonizing the plant rhizosphere (Busch et al. 1978; Edel et al. 1997), or as soil inhabitants (Demers et al. 2015). Plant-microbe interactions are often overlooked by plant pathologists in the absence of disease symptoms or outside of an agricultural context, although these asymptomatic interactions have been the subject of significant ecological research (Burdon 1991; Burdon et al. 2006; Gilbert 2002) and are very relevant for disease epidemiology and management. For example, from a phytopathological perspective, plants on which symptoms have not been yet observed for a given disease are considered to be nonhosts of the pathogen. However, some studies indicate that asymptomatic plant

†Corresponding author: M. M. Jiménez-Gasco; jimenez-gasco@psu.edu

Funding: Support was provided by the United States-Israel Binational Agricultural Research and Development Fund (BARD) Research Grant Award US-4839-15 FR, and National Institute of Food and Agriculture Federal Appropriations Projects PEN04655 and PEN04676 (accession numbers 1016291 and 1017795). Findings and conclusions of this research do not necessarily reflect the view of the funding agency.

*The $e$-Xtra logo stands for "electronic extra" and indicates that supplementary tables are published online.

The author(s) declare no conflict of interest.

(c) 2021 The American Phytopathological Society hosts can serve as cryptic or hidden reservoirs of microbial diversity (Evans 1971; Xin et al. 2018), including plant pathogens. This has led us to use interactions with pathogens to classify plants into "symptomatic"-plant species displaying visible disease symptoms as a consequence of microbial infection-and "asymptomatic"-plant species in which endophytic colonization does not result in detectable disease - thus leaving the term "nonhost" to refer to plant species that do not interact with the given microbe (Malcolm et al. 2013). Similarly, some microbial communities found in the environment such as in soil or in water may also be sources of pathogen diversity and inoculum contributing to epidemics in agroecosystems (Monteil et al. 2013, 2016; Tsror (Lahkim) et al. 2020). However, for most plant-microbe interactions, the role of asymptomatic hosts and the diversity of pathogens associated with them remain relatively unknown. Tsror (Lahkim) et al. (2020) recently reported alternative hosts of Spongospora subterranea, the causal agent of powdery scab on potato, which allow multiplication and survival of the pathogen over time. S. subterranea was detected in 16 weed species from eight families and in volunteer plants of wheat, sampled in potato fields with history of powdery scab. Whether asymptomatic plants act as reservoirs that have roles in the evolution of pathogen populations and epidemic dynamics in subsequent susceptible crops (Stergiopoulos and Gordon 2014; Suproniene et al. 2019; Wang et al. 2010) is an important question that still needs to be addressed for many plant pathogens and may be especially relevant for designing effective disease management strategies in agroecosystems.

Verticillium dahliae is a soilborne fungal pathogen of many economically important crops that can also infect weeds and rotational crops without causing apparent disease symptoms (Evans 
1971; Malcolm et al. 2013; Wheeler and Johnson 2016). V. dahliae is most prevalent in temperate and Mediterranean climates and has a broad range of susceptible hosts of over 300 plant species (Pegg and Brady 2002). Verticillium wilt is one of the most difficult diseases to manage because of the limited availability of disease-resistant cultivars. Management primarily targets the reduction of inoculum in soil. V. dahliae produces long-lived microsclerotia, which are highly melanized structures that can survive in the environment for long periods of time in the absence of a host plant. Reduction in inoculum is achieved primarily by soil disinfestation using fumigants and rotations with crops that do not develop symptoms, whether asymptomatic or true nonhosts (Rowe and Powelson 2002; Rowe et al. 1987; Tsror (Lahkim) et al. 2005). In theory, crop rotations with asymptomatic and nonhost species are important for managing plant diseases to avoid the inoculum build-up resulting from constant cultivation of symptomatic, susceptible crops. Rotations are also a more environmentally sustainable alternative to soil fumigation for managing Verticillium wilts (Davis and Huisman 2004).

Crop rotations often have inconsistent effects for reducing Verticillium wilt of potato, and those effects largely depend on the sequence and length of the rotation and soil type (Busch et al. 1978; Davis et al. 1996, 1999a, b; Joaquim et al. 1988; Larkin et al. 2011). For example, in Israel, potato cultivation includes 3 to 4 years of rotation between potato crops; this relatively short period results in little reduction in Verticillium wilt and requires fumigation, which is done once every few cycles depending on cultivar susceptibility and soil inoculum levels (Cohen et al. 2012). Previous research showed that some rotational crops and weeds can be asymptomatically infected by V. dahliae in the field (Demirci and Genc 2009, 2011; Evans 1971; Krikun and Bernier 1987, 1990; Malcolm et al. 2013; Wheeler and Johnson 2016; Wheeler et al. 2019). In addition, $V$. dahliae can colonize the surface of roots and produce microsclerotia on rotational crops and weeds even though it may not colonize systemically (Busch et al. 1978; Evans 1971; Evans and Gleeson 1973; Harrison and Isaac 1969; Lacy and Horner 1966; Levy and Isaac 1976; Mol 1995).

Populations of $V$. dahliae comprise a limited number of clonal lineages that correlate with vegetative compatibility groups (VCGs) and can be identified by single-nucleotide polymorphism (SNP) genotyping (Milgroom et al. 2014, 2016; Rafiei et al. 2018). Diversity of $V$. dahliae has been extensively studied in populations associated with symptomatic hosts in different geographical regions (Atallah et al. 2010; Iglesias-Garcia et al. 2013; JiménezDíaz et al. 2011, 2012; Joaquim and Rowe 1991; Schnathorst and Mathre 1966; Tsror (Lahkim) et al. 2001). For example, in Israel, lineages 4B, 2A, and 2B (inferred by VCG) were identified among $V$. dahliae isolates causing disease in cotton, potato, tomato, and other vegetable crops, whereas lineage $1 \mathrm{~A}$, the defoliating pathotype, was only identified from cotton in the northern region of the country (Korolev et al. 2000, 2001, 2008). Isolates of lineage 2B were recovered both from northern and southern parts of Israel while $4 \mathrm{~B}$ isolates were found mostly in the south, where potato is primarily grown. In the United States, $V$. dahliae lineages 2A, 2B, $4 \mathrm{~A}, 4 \mathrm{~B}$, and 6 (inferred from VCGs) affect potato and other vegetable crops. Isolates from lineages $4 \mathrm{~A}$ and $4 \mathrm{~B}$ are highly aggressive toward most potato cultivars and predominant in potato fields (Bhat et al. 2003; Dung et al. 2013; Joaquim and Rowe 1991). In contrast, few studies have investigated the genetic diversity of $V$. dahliae populations found in asymptomatic hosts. For example, Demirci and Genc $(2009,2011)$ isolated V. dahliae lineages $2 \mathrm{~B}$ and 4B (inferred from VCGs) from asymptomatic weeds in Turkish potato fields, and Wheeler et al. (2019) observed that $V$. dahliae isolates pathogenic to potato were recovered from asymptomatic rotational crops collected from potato fields in Washington State. It is important to elucidate whether asymptomatic hosts in potato fields serve as reservoirs of $V$. dahliae lineages $4 \mathrm{~A}$ and 4B, which are aggressive on potato. If inoculum is produced in asymptomatic rotational crops and weeds, it could contribute to the initiation of epidemics in subsequent potato crops. If inoculum is produced in asymptomatic hosts that is effective on a primary crop such as potato, we predict that the same pathogen genotypes would be found in both symptomatic crops and asymptomatic rotational crops or weeds.

The main objective of this study was to test the hypothesis that $V$. dahliae populations recovered from asymptomatic rotational crops and weeds are genetically distinct from those infecting symptomatic susceptible crops such as potato. A second objective was to investigate the genetic structure and evolution of the lineages associated with asymptomatic hosts. These objectives were addressed by using an SNP dataset generated by genotyping-bysequencing (GBS) to analyze the evolutionary history and genetic differentiation of $V$. dahliae populations collected from fields with histories of Verticillium wilt of potato in Israel and Pennsylvania (United States).

\section{MATERIALS AND METHODS}

Isolates of $\boldsymbol{V}$. dahliae. $V$. dahliae was sampled from symptomatic and asymptomatic hosts grown in fields with histories of Verticillium wilt in Israel and Pennsylvania (United States). In Israel, most sampling was done in the southern region of the country which is the main potato-growing area. Sampling was done in fields that had been planted to potato 1 to 3 years prior to sampling. $V$. dahliae was isolated from volunteer potato plants or rotational crops such as sorghum and sunflower, and from weeds (asymptomatic hosts) growing in the same fields. In addition to sampling in southern Israel, we attempted to isolate $V$. dahliae from various crops and weeds in several cultivated fields with diverse cropping histories in central and northern Israel; none had a history of potato production. In Pennsylvania, we sampled $V$. dahliae from potato 'Snowden' and 'Reba' and oat 'Armor' in fields located in Ringtown (Schuylkill County) with a history of Verticillium wilt, as described by Malcolm et al. (2013). Oat was planted as a rotational crop in this field and considered an asymptomatic host. Isolation of $V$. dahliae was performed as described by Tsror (Lahkim) and Levin (2003) and Malcolm et al. (2013). Prior to SNP genotyping, we performed VCG typing on a large subset of the Pennsylvania or Israel isolates to confirm the correlation between SNP-derived lineages and VCGs. VCG typing was done using standard methods for $V$. dahliae (Tsror (Lahkim) and Levin 2003). In addition to sampling from symptomatic and asymptomatic hosts, we included nine additional isolates from various crops as representatives of known VCGs or lineages that we assumed may present larger genetic diversity; therefore, these isolates were only used for the phylogenetic analysis in our study (Supplementary Table S1). These nine isolates originated from cotton $(\mathrm{GVd} 20=$ VCG1A, and GVd57 and GVd96 = VCG2B), olive $(\mathrm{GVd} 56=$ VCG2A, and GVd97 = VCG2B), tomato $($ GVd108 = VCG2A, and GVd107 = VCG4B $)$, chrysanthemum $($ GVd105 = VCG2B $)$, and eggplant $(\mathrm{GVd} 85$ = VCG4B $)$.

Genomic DNA and GBS. Single-spore cultures were grown on potato dextrose agar (Difco, Franklin Lakes, NJ, U.S.A.) for 5 to 7 days at room temperature. Sterile water $(2 \mathrm{ml})$ was added to the surface of the plate and the plate was scraped to release mycelia and spores. Mycelia and spores were collected, lyophilized, and ground to fine powder using sterile pestles. Genomic DNA from Pennsylvania isolates was extracted from $25 \mathrm{mg}$ of lyophilized material with the UltraClean Tissue \& Cells DNA Isolation Kit (MoBio Laboratories, Carlsbad, CA, U.S.A.) following the manufacturer's instructions. Nucleic acid purity and concentration were assessed on a Nanodrop spectrophotometer (Nanodrop Technologies, Wilmington, DE, U.S.A.). DNA of isolates from Israel was extracted using Maxwell 16 Tissue DNA Purification Kit (Promega Corporation, Madison, WI, U.S.A.) according to the manufacturer's protocol. Genomic DNA quality was assessed by enzymatic digestion with HindIII (New England BioLabs, Ipswich, 
MA, U.S.A.) and electrophoresis on $0.8 \%$ agarose gel. Genomic DNA samples were submitted to the Beijing Genomics Institute (BGI, Shenzhen, China) for GBS (Elshire et al. 2011). Briefly, genomic DNA was digested with the restriction enzyme ApeKI to generate a reduced-representation library. Oligonucleotide adapters and sample-specific barcodes were ligated to the restriction fragments for PCR and sequencing on Illumina HiSeq 4000. Paired-end reads of $100 \mathrm{bp}$ from the ends of the restriction fragments were generated and separated by taxa (i.e., sample). Barcode- and adapter-free quality sequencing reads were provided by BGI for further bioinformatic analysis.

Variant calling and assignment of $V$. dahliae isolates to clonal lineages based on SNP markers. SNP genotyping and assignment of $V$. dahliae isolates to clonal lineages was performed as described previously (Milgroom et al. 2014, 2016; Rafiei et al. 2018), following the recommendations from Grünwald et al. (2016). Reads were aligned to the $V$. dahliae reference genome VdLs.17 (GenBank accession GCA_000952015.1) (Klosterman et al. 2011), using the Burrows-Wheeler Alignment Tool (BWA mem option) (Li 2013) with default parameters for paired-end reads. Samtools v1.4.1 (Li et al. 2009) and Sambamba v0.6.6 (Tarasov et al. 2015) were used to sort aligned read files and mark duplicates using the functions samtools view-Shu, sambamba sort, and sambamba markdup. Joint variant calling was performed using Freebayes v1.1.0-9-g09d4ecf (Garrison and Marth 2012) with $-f$ function and default parameters. Sites containing putative variants were filtered with vcffilter (vcflib from Freebayes) $-f$ function for SNP sites with read depth $>5$ and mapping quality $>30$ in individual samples. Subsequent analyses were performed on SNP datasets of Pennsylvanian or Israeli isolates alone and together with SNP data from representatives of $V$. dahliae clonal lineages. Unfiltered SNP data from 33 representatives of $V$. dahliae clonal lineages 1A, 2B ${ }^{334}$, $4 \mathrm{~A}, 6,2 \mathrm{~B}^{\mathrm{R} 1}, 2 \mathrm{~B}^{824}, 2 \mathrm{~A}$, and $4 \mathrm{~B}$ (Milgroom et al. 2014) were included. All heterozygous values (caused infrequently by sequencing or alignment errors) were recorded as missing data, as described previously (Milgroom et al. 2014, 2016; Rafiei et al. 2018), and the merged dataset was filtered using TASSEL V5.2.38 (Bradbury et al. 2007). All sites were filtered for a minimum minor allele frequency of $1 \%$ and allele information in at least $75 \%$ of the samples. Monomorphic sites and samples that did not have information in at least $50 \%$ of the sites were excluded. Filtered SNP positions were used to assign Pennsylvanian and Israeli isolates to clonal lineages previously defined (Milgroom et al. 2014). A neighbor-joining phylogeny was inferred on the filtered SNP dataset using the maximum-composite-likelihood model and 1,000 bootstraps of the data with pairwise deletion option for missing allele data in MEGA7 (Kumar et al. 2016).

Genetic structure of $V$. dahliae lineage 4B populations. Diversity and structure of $V$. dahliae lineage 4B populations from Pennsylvanian and Israeli potato fields were further analyzed. In TASSEL, raw SNP data from lineage 4B isolates from potato fields were filtered for sites with a minimum minor allele frequency of $1 \%$ and allele information in $100 \%$ of the samples. Monomorphic sites were excluded. To explore the genetic structure of lineage 4B isolates, we used k-means and the Bayesian Information Criterion (BIC) method, a clustering algorithm to identify genetic groups without prior definition after transforming data using a principal component analysis (Jombart et al. 2010). The discriminant analysis of principal components (DAPC) was used to visualize the variation between and within clusters in the $\mathrm{R}$ package adegenet 2.1.2 (Jombart 2008) in R 3.6.2 (R Core Team 2020). Briefly, genetic clusters were identified using find.clusters function with options max.n.clust $=60$ and n.pca $=100$, and the DAPC graph was built using the genetic clusters previously identified, dapc and scatter.dapc functions.

Genetic relationships among lineage 4B isolates were explored using a minimum spanning network (MSN) with bitwise.dist function set for Hamming distance, which calculates the number of allelic differences between samples, and popprmsn in the $\mathrm{R}$ package poppr 2.8.3 (Kamvar et al. 2014). In addition, a coalescent genealogy was inferred to investigate the ancestry of lineage $4 \mathrm{~B}$ isolates from potato fields. Coalescent analyses were performed on Mobyle SNAP Workbench (Monacell and Carbone 2014) using the program Genetree (Bahlo and Griffiths 2000) and the workflow instructions for Genetree provided at http://snap.hpc.ncsu.edu/cgibin/mobyle/portal.py\#welcome. Only parsimony-informative sites and sites without missing data or gaps were included in the analysis. The data set was analyzed in RDP4 (Martin et al. 2015) to confirm the absence of recombination among the selected sites. In order to reconstruct the mutation history of the alignment, we performed 1 million runs of the data starting from three different seed numbers.

Genetic differentiation of $V$. dahliae populations from symptomatic and asymptomatic hosts. In order to investigate whether $V$. dahliae populations from symptomatic and asymptomatic hosts were genetically differentiated, analyses were focused on lineage $4 \mathrm{~B}$ because all isolates from asymptomatic hosts sampled from potato fields were placed in this lineage (see Results). Two populations were established based on the symptomatology of the host from which they were isolated: symptomatic (originating from symptomatic hosts) and asymptomatic (originating from asymptomatic hosts). First, analysis of molecular variance (AMOVA) was performed to analyze the genetic differentiation between the symptomatic and asymptomatic populations of $V$. dahliae lineage 4B. Second, AMOVA was conducted to detect the level of differentiation between populations within each of the lineage 4B genetic clusters identified by k-means and BIC.

Analyses were performed on SNPs with at least $1 \%$ minor allele frequency and no missing allele information to test the null hypothesis that $V$. dahliae populations were not genetically differentiated. Tests were performed in poppr using poppramova to estimate $\Phi$, analogous to fixation index $\left(F_{\mathrm{ST}}\right)$ (Excoffier et al. 1992) with threshold $=0.1$ and filter $=$ TRUE. Data were randomly permuted 999 times with the function randtest from the R package ade4 1.7-13 (Chessel et al. 2004). The genetic relationship of isolates from both populations were also explored using the MSN as described above.

Data availability. All files with SNP data and scripts used for the analyses in this study can be accessed at GitHub (https:// github.com/laurabau/BautistaJalon_Vdahliae).

\section{RESULTS}

Isolates of $\boldsymbol{V}$. dahliae. We obtained a total of $132 \mathrm{~V}$. dahliae isolates from symptomatic $(n=78)$ and asymptomatic hosts $(n=54)$ in Israel and Pennsylvania (Table 1; Supplementary Table S1). In Israel, we obtained 27 isolates from symptomatic crops and 41 isolates from asymptomatic crops and weeds. Although central and northern Israel were sampled intensively, most isolates, including all obtained from asymptomatic samples, were collected from fields with recent potato cropping history located in the south $(n=66)$. Despite attempts to isolate from many plants in central and northern Israel, we only obtained two isolates from symptomatic hosts in these regions. $V$. dahliae isolates from Pennsylvania $(n=64)$ were collected from symptomatic potato 'Snowden' and 'Reba' $(n=51)$ and asymptomatic 'Armor' oat plants $(n=13)$. All isolates sampled from Israel were typed to VCG except two (GVd35 and GVd54). All isolates collected from Israel from asymptomatic hosts were in VCG4B $(n=40)$, whereas isolates collected from symptomatic hosts were in VCGs $2 \mathrm{~A}(n=3), 2 \mathrm{~B}$ $(n=4)$, and 4B $(n=19)$. In total, 30 isolates from the 64 isolates from Pennsylvania were typed to VCG (24 isolates from the symptomatic host potato and 6 from the asymptomatic host oat). Isolates from potato were in VCGs $2 \mathrm{~A}(n=2), 4 \mathrm{~B}(n=11)$, and 4A $(n=11)$, whereas all isolates from oat were in VCG4B (Supplementary Table S1).

SNP genotyping and phylogenetic structure of $\boldsymbol{V}$. dahliae populations. In total, 136,683 SNP sites were detected with Freebayes and vcffilter among $V$. dahliae isolates from Pennsylvania and Israel. After merging and filtering the SNP dataset from 
Pennsylvania and Israel with unfiltered SNP data from $V$. dahliae lineage representatives (Milgroom et al. 2014), six isolates (Supplementary Table S1) were excluded because they were missing data at $>50 \%$ of the SNP loci. We inferred the evolutionary history of $V$. dahliae using 26,934 SNPs distributed throughout the genome of 168 V. dahliae isolates (Fig. 1; Supplementary Table S2). This set included 59 isolates from Pennsylvania and 67 from Israel; in addition, it included 33 reference isolates for clonal lineages identified by SNP genotyping (Milgroom et al. 2014) and 9 reference isolates of known VCGs from Israel (Korolev et al. 2000, 2008).

The neighbor-joining phylogeny comprises three main clades with subclades that correlate to VCGs (Fig. 1). It is concordant with the phylogenetic structure observed in previous studies (Milgroom et al. 2014; Rafiei et al. 2018), except for the location of 2B $\mathrm{B}^{\mathrm{R}}$, which was closely related to $2 \mathrm{~B}^{824}$ and 6 in this study instead of $1 \mathrm{~A} / 1 \mathrm{~B}$ and $2 \mathrm{~B}^{334}$ as in Milgroom et al. (2014).

Pennsylvanian isolates from symptomatic potato $(n=50)$ were placed in lineages $2 \mathrm{~A}, 4 \mathrm{~A}$, and $4 \mathrm{~B}(n=2,18$, and 30 isolates, respectively), as expected from their VCG phenotypes. Pennsylvanian isolates from oat $(n=9)$, an asymptomatic rotational host, were found only in lineage 4B. Israeli isolates recovered from symptomatic hosts were placed in lineages $2 \mathrm{~A}, 2 \mathrm{~B}^{824}$, and $4 \mathrm{~B}(n=4,4$, and 19 isolates, respectively), as expected from their VCG phenotypes. These isolates were obtained from mango, olive, avocado, potato, eggplant, pepper, cantaloupe, watermelon, and sunflower (Table 1). Isolates sampled from asymptomatic hosts $(n=40)$ clustered solely in lineage $4 \mathrm{~B}$ and were recovered from weeds, peanut, and sorghum (Table 1). Isolates in lineage 4A were obtained only from potato in Pennsylvania (Fig. 1).

Genetic structure of $V$. dahliae lineage 4B populations. All $V$. dahliae isolates from asymptomatic hosts were placed in lineage $4 \mathrm{~B}$ together with some isolates from symptomatic hosts (Table 1). Lineage 4B comprised the largest group of $V$. dahliae individuals in this study, with a total of 98 isolates, $77 \%$ of the isolates sampled $(n=59$, Israel and $n=39$, Pennsylvania).

We identified 1,343 SNPs with no missing allele information, $1 \%$ minor allele frequency, and randomly distributed throughout the genomes of 98 lineage 4B isolates (Supplementary Table S2). Using the k-means clustering algorithm, the BIC values suggested an optimal number of three or four genetic clusters (Fig. 2). Four clusters were selected $(k=4)$, corresponding to three groups containing Pennsylvanian isolates (PA_1,PA_2, and PA_3) and one group of Israeli isolates, independent of the symptomatology of the host of origin.

Variation among the genetic clusters was visualized in DAPC using two principal components and two discriminant functions (DA eigenvalues). Both DAPC and MSN analyses showed three main groups, with PA_3 and Israeli populations plotted close to each other in one large group but distant from PA_1 and PA_2.PA_1 and PA_2 were also distant between themselves (Figs. 2 and 3A) and positioned in different quadrants.

Coalescent analysis was performed for 98 individuals using 158 parsimony-informative SNPs with no missing data to infer the genealogy of lineage 4B isolates (Fig. 4). RDP4 detected no recombination signals in the SNP alignment, which fulfilled necessary assumptions for coalescent analysis. In total, 24 haplotypes were identified. The inferred genealogy showed a topology concordant with four genetic clusters. Isolates in the Israeli and PA_3 clusters formed two distinct groups that coalesced with each other before they coalesced with clusters PA_1 and PA_2. Israeli isolates grouped into 12 haplotypes in a single clade. In all, 38 of the 59 Israeli isolates were characterized as haplotype H6 and were obtained from a variety of symptomatic hosts $(n=16)$ such as potato, tomato, olive, and avocado but also from asymptomatic

TABLE 1. Verticillium dahliae isolates sampled in this study from symptomatic and asymptomatic hosts by geographic location and host, and their clonal lineage placement

\begin{tabular}{|c|c|c|c|c|c|}
\hline Location, symptomatology ${ }^{a}$ & $\begin{array}{l}\text { Host plant } \\
\text { family }\end{array}$ & $\begin{array}{l}\text { Number of } \\
\text { isolates }\end{array}$ & Crop & Clonal lineage $^{\mathrm{b}}$ & Haplotype $^{c}$ \\
\hline \multicolumn{6}{|l|}{ Israel } \\
\hline \multirow[t]{6}{*}{ Asymptomatic $(n=41)$} & Amaranthaceae & 6 & Weed & $4 \mathrm{~B}$ & H6, H10, H11 \\
\hline & Boraginaceae & 11 & Weed & $4 \mathrm{~B}$ & H5, H6, H7, H15, H16 \\
\hline & Brassicaceae & 12 & Weed & 4B & H6, H9, H12, H14 \\
\hline & Convolvulaceae & 1 & Weed & 4B & $\mathrm{H} 14$ \\
\hline & Fabaceae & 1 & Peanuts & 4B & H6 \\
\hline & Solanaceae & 2 & Weed & 4B & H6, H12 \\
\hline \multirow{6}{*}{ Symptomatic $(n=27)$} & Anacardiaceae & 1 & Mango & $4 \mathrm{~B}$ & H6 \\
\hline & Asteraceae & 2 & Sunflower & 4B & H6 \\
\hline & Cucurbitaceae & 2 & Cantaloupe $(n=1)$ & $4 \mathrm{~B}$ & H6 \\
\hline & $\ldots$ & $\ldots$ & Watermelon $(n=1)$ & 4B & H6 \\
\hline & Lauraceae & 2 & Avocado & 4B & H6 \\
\hline & Oleaceae & 3 & Olive & $2 \mathrm{~A}(n=1)$ & ND \\
\hline \multicolumn{6}{|l|}{ Pennsylvania, United States } \\
\hline Asymptomatic $(n=13)$ & Poaceae & 13 & Oat & 4B $(n=9), \mathrm{ND}(n=4)$ & $\mathrm{H} 2, \mathrm{H} 3, \mathrm{H} 17, \mathrm{H} 22$ \\
\hline \multirow[t]{4}{*}{ Symptomatic $(n=51)$} & Solanaceae & 51 & Potato & $2 \mathrm{~A}(n=2)$ & ND \\
\hline & $\ldots$ & $\ldots$ & $\ldots$ & $4 \mathrm{~A}(n=18)$ & ND \\
\hline & $\cdots$ & $\cdots$ & $\cdots$ & 4B $(n=30)$ & $\begin{array}{c}\mathrm{H} 1, \mathrm{H} 2, \mathrm{H} 4, \mathrm{H} 17, \mathrm{H} 18, \mathrm{H} 19, \mathrm{H} 20, \mathrm{H} 21, \\
\mathrm{H} 23, \mathrm{H} 24\end{array}$ \\
\hline & $\ldots$ & $\ldots$ & $\ldots$ & $\mathrm{ND}(n=1)$ & ND \\
\hline
\end{tabular}


hosts $(n=22)$ such as weed species in the families Brassicaceae, Asteraceae, and Boraginaceae. This haplotype can also be considered the ancestral state of the Israeli population of lineage $4 \mathrm{~B}$ because there are no mutations that differentiate it from the most recent common ancestor of this clade (Fig. 4). Other isolates obtained from symptomatic hosts were in haplotypes $\mathrm{H} 8$ and $\mathrm{H} 9$. Isolates from asymptomatic hosts were in haplotypes $\mathrm{H} 6, \mathrm{H} 9$, and nine other haplotypes (H5, H7, H10, H11, H12, H13, H14, H15, and H16). Isolates from Pennsylvania were also found in 12 different haplotypes, with one predominant haplotype (H17 in PA_1 clade)

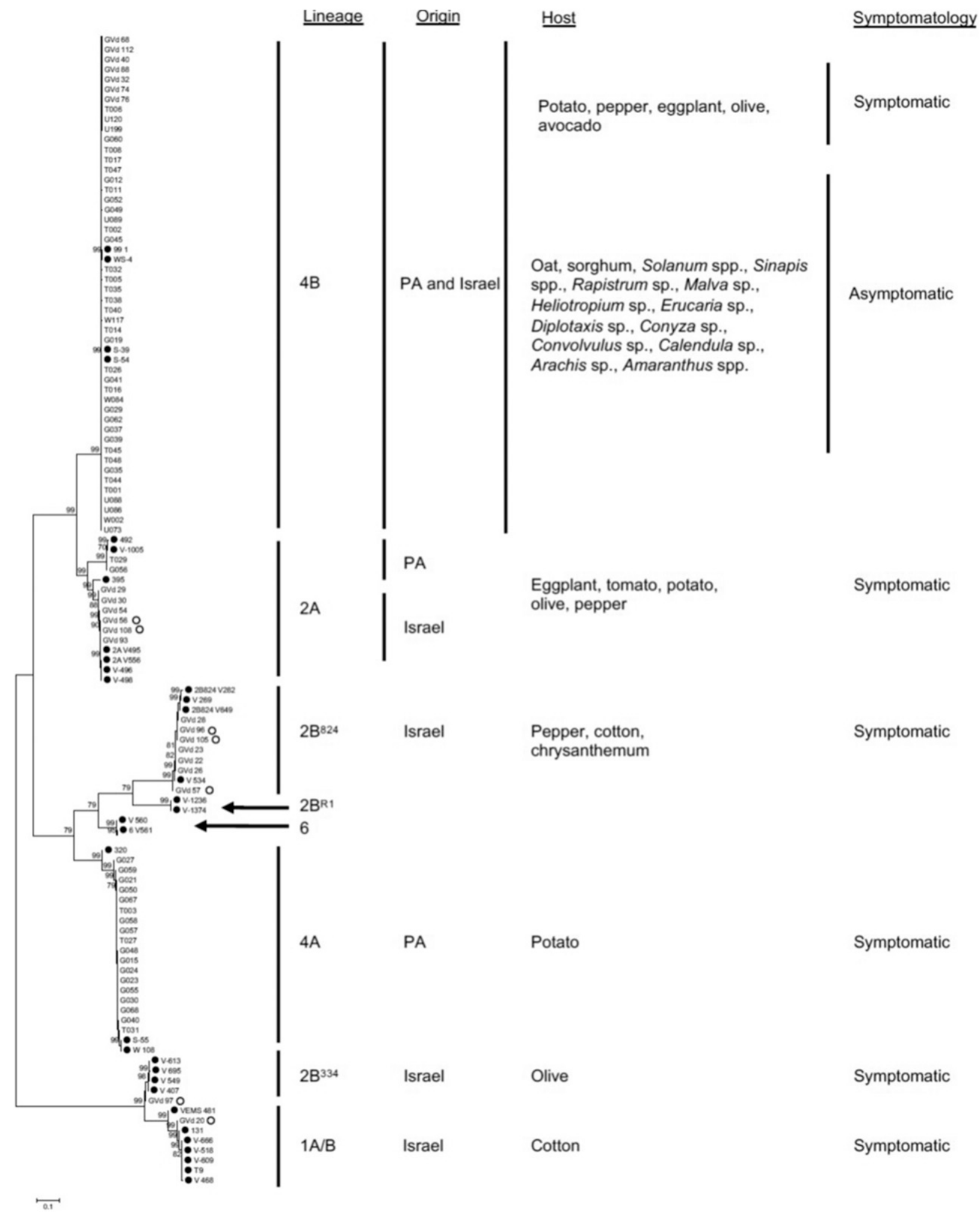

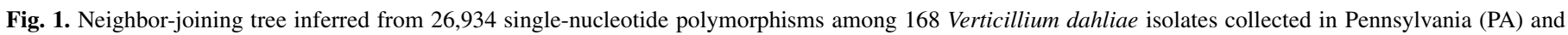
Israel. Branch bootstrap supports $<70 \%$ are omitted. Thirty-three $V$. dahliae reference isolates, representative of clonal lineages $1 \mathrm{~A}, 2 \mathrm{~A}, 2 \mathrm{~B}^{334}, 2 \mathrm{~B}^{824}, 2 \mathrm{~B}^{\mathrm{R} 1}, 4 \mathrm{~A}$, 4B, and 6 (Milgroom et al. 2014), are indicated by solid circles. Israeli lineage or vegetative compatibility group reference isolates are indicated with open circles. Geographic origin, host, and symptomatology of the host of $V$. dahliae isolates are shown on the right side. Only 50 selected isolates of 98 isolates in lineage 4B are included in the figure to reduce the figure size. Missing allele data were excluded from this analysis. 
comprising nine isolates from potato (symptomatic host) and five from oat (asymptomatic host). Two haplotypes (H2 and $\mathrm{H} 17$ in PA_ 3 and PA_1, respectively) contained isolates from both symptomatic (potato) and asymptomatic (oat) hosts. Eight haplotypes had isolates only from the symptomatic host, potato $(\mathrm{H} 1, \mathrm{H} 4, \mathrm{H} 18, \mathrm{H} 19$, $\mathrm{H} 20, \mathrm{H} 21, \mathrm{H} 23$, and H24), while two haplotypes included only isolates from the asymptomatic host, oat (H3 and H22).

Genetic differentiation of $V$. dahliae populations from symptomatic and asymptomatic hosts. All V. dahliae isolates
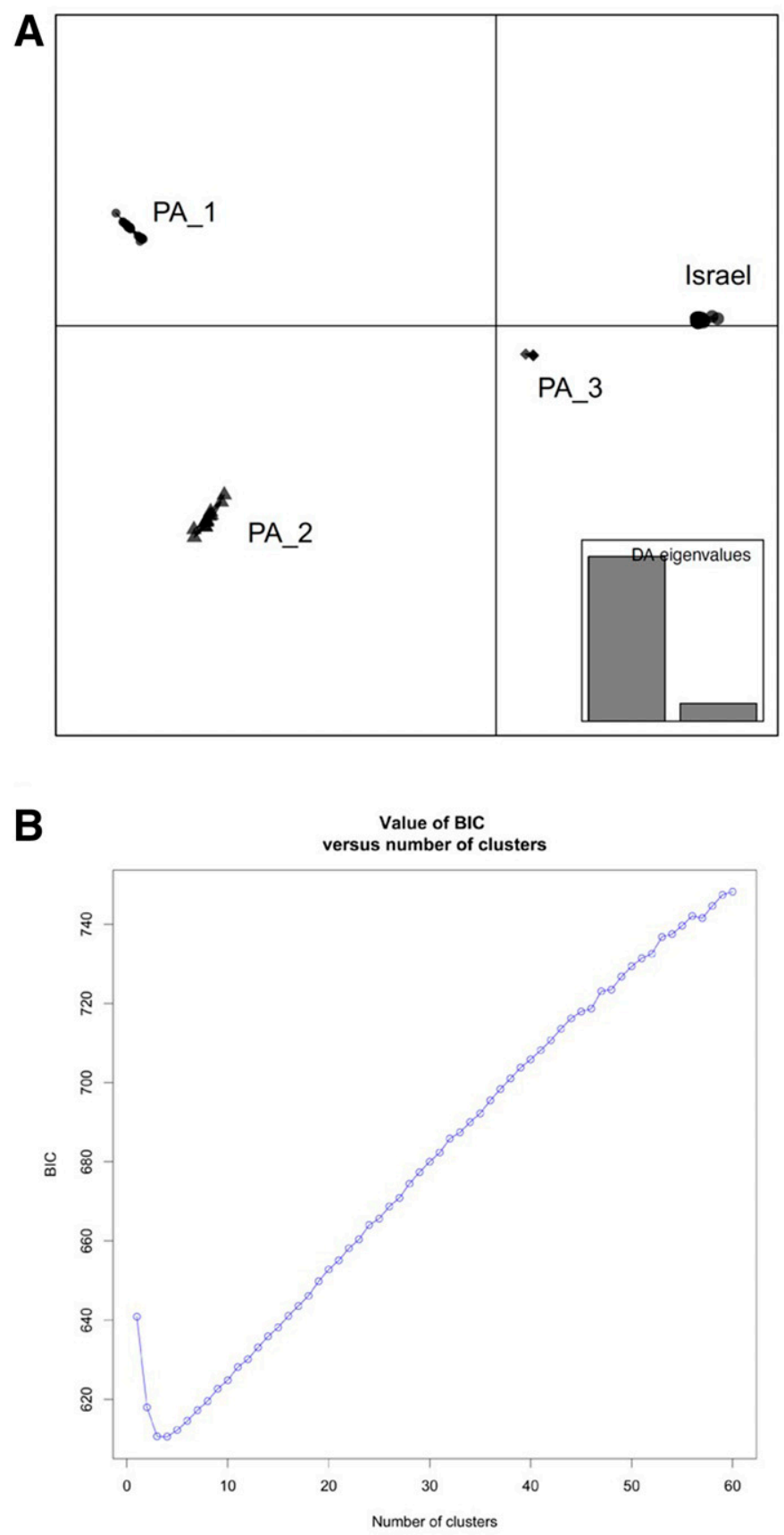

Fig. 2. A, Discriminant analysis of principal components of Verticillium dahliae lineage 4B isolates from Pennsylvanian and Israeli potato fields. The analysis was performed on 1,343 single-nucleotide polymorphisms and 98 individuals using the adegenet $\mathrm{R}$ package. Genetic clusters were identified using k-means and Bayesian Information Criterion (BIC). Genetic variation was visualized using two principal components and two discriminant functions. B, Values of BIC versus number of genetic clusters in $V$. dahliae lineage 4B isolates from Pennsylvania and Israel. Isolates from asymptomatic hosts grouped in each of the four genetic clusters identified together with isolates from symptomatic hosts. recovered from asymptomatic hosts were in lineage 4B; however, isolates recovered from symptomatic hosts were in lineages $2 \mathrm{~A}$, $2 \mathrm{~B}^{824}$, and 4B (isolates from Israel) and 2A, 4A, and 4B (isolates from Pennsylvania). This disparity in lineage diversity indicates that populations from symptomatic and asymptomatic hosts are differentiated (Table 1). Focusing on lineage 4B, results from AMOVA showed that isolates from symptomatic hosts and asymptomatic hosts were strongly differentiated $(\Phi=0.1405, P=$ 0.001 ) (Table 2) when all isolates were analyzed together without taking population structure into account. However, no genetic differentiation was found between isolates from symptomatic and asymptomatic hosts within three of the genetic clusters Israel, PA_ 1, and PA_2 $(P>0.1)$; isolates from genetic cluster PA_3 could not be compared because of the small sample size $(n=3)$, and PA_2 only included two isolates from asymptomatic hosts; therefore, we should be cautious when drawing conclusions given the unbalanced number of isolates in this cluster. In addition, the MSN showed that isolates from asymptomatic hosts were genetically highly similar to isolates collected from symptomatic hosts from the same genetic cluster (Fig. 3B). Therefore, the strong differentiation that was initially observed between isolates from symptomatic hosts and asymptomatic hosts when genetic clusters were not taken into account reflects a confounding effect caused by genetic structure.

\section{DISCUSSION}

The main goal of this research was to test the hypothesis that $V$. dahliae populations recovered from rotational crops and weeds-asymptomatic hosts - are evolutionarily and genetically distinct from those infecting susceptible crops such as potatosymptomatic hosts. To test this hypothesis, the phylogenetic diversity and the genetic differentiation of $V$. dahliae populations collected from asymptomatic and symptomatic hosts in Israel and Pennsylvania were analyzed with a large dataset of SNPs generated by GBS. Overall, $V$. dahliae isolates from symptomatic hosts were placed in previously known lineages $2 \mathrm{~A}, 2 \mathrm{~B}^{824}, 4 \mathrm{~A}$, and 4B. However, isolates recovered from asymptomatic hosts were all characterized as members of lineage 4B, indicated both by SNP genotyping and VCG phenotyping. The high lineage diversity found in populations infecting symptomatic hosts is consistent with previous research in North America and Israel (Bhat et al. 2003; Dung et al. 2013; Joaquim and Rowe 1991; Korolev et al. 2000, 2001, 2008; Tsror (Lahkim) et al. 2001). A few isolates from Israel recovered from symptomatic eggplant, pepper, and olive were placed in lineages $2 \mathrm{~B}^{824}$ and $2 \mathrm{~A}$, and a small subset of isolates from Pennsylvania infecting potato were characterized as lineage $2 \mathrm{~A}$. Lineages $2 \mathrm{~A}$ and $2 \mathrm{~B}^{824}$ are not as frequently associated with potato as lineages $4 \mathrm{~A}$ and $4 \mathrm{~B}$ but, rather, are lineages that generally affect other solanaceous crops (Dung et al. 2013; Tsror (Lahkim) et al. 2001).

Endophytic or epiphytic fungi that do not cause overt symptoms on asymptomatic hosts may have the potential to affect susceptible crop plants (symptomatic hosts). Such asymptomatic hosts represent hidden ecological niches that could serve as reservoirs of plant pathogens. They are significant for disease management because they have the potential to (i) maintain pathogen diversity and (ii) maintain populations that are pathogenic to other crops and can contribute inoculum to initiate new field-level epidemics, thus bypassing the benefits of crop rotation (Evans 1971; Monteil et al. 2013, 2016; Xin et al. 2018). Our results indicate that asymptomatic weeds and rotational crops did not harbor a diverse $V$. dahliae population, because isolates from these hosts were exclusively in lineage $4 \mathrm{~B}$, a lineage with the potential to cause disease to a broad range of susceptible hosts (Berbegal et al. 2010; Chandelier et al. 2003; Iglesias-Garcia et al. 2013; Tsror (Lahkim) et al. 2001). Lineage $4 \mathrm{~B}$ was also the predominant lineage among $V$. dahliae isolates infecting a wide range of symptomatic hosts in this study.

There was no significant differentiation of lineage $4 \mathrm{~B}$ isolates between populations on symptomatic and asymptomatic hosts. 


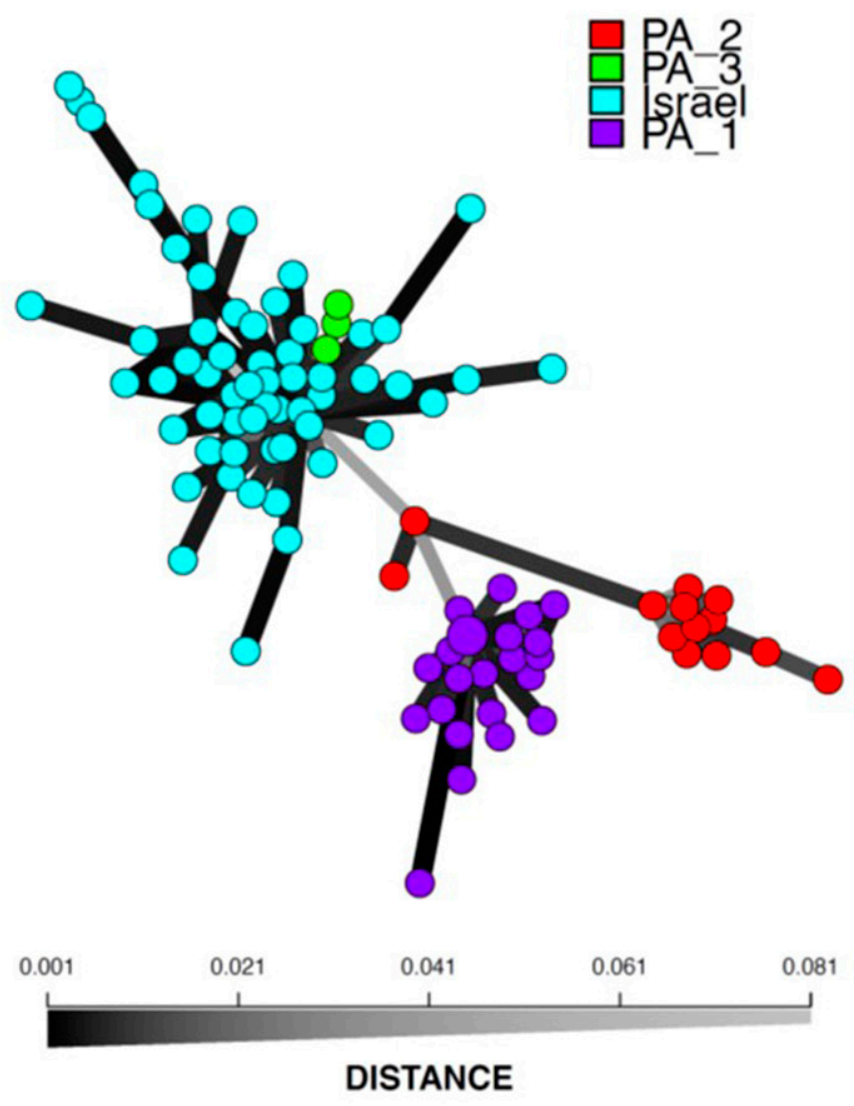

B
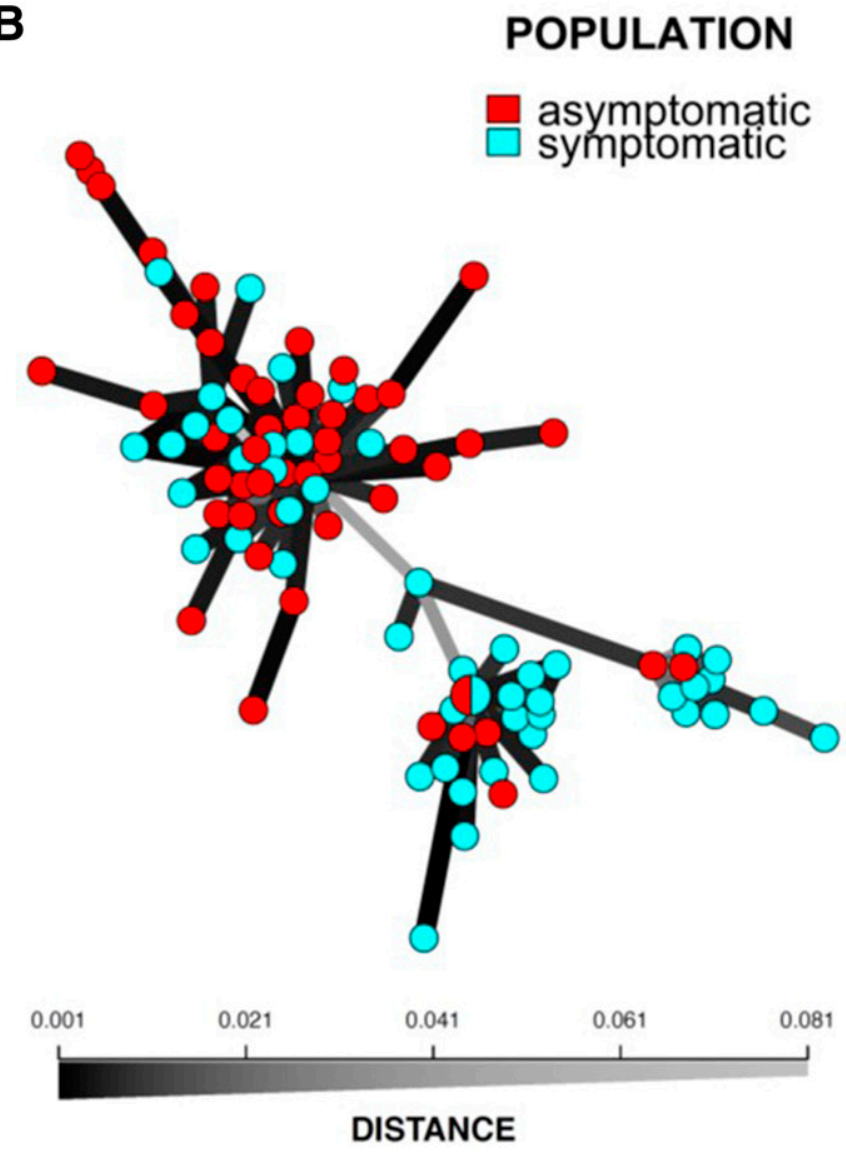

Isolates infecting host plants as endophytes were often closely related to isolates from susceptible hosts (symptomatic hosts), as illustrated in the MSN and the coalescent analysis (Figs. 2 and 3). Additionally, recent studies in greenhouse conditions showed that $V$. dahliae isolates that are pathogenic to common susceptible hosts could asymptomatically infect a variety of rotational crops and weed species typically found in U.S. potato fields (Frederick et al. 2017; Wheeler and Johnson 2016), and that V. dahliae isolates collected from asymptomatic hosts caused disease in potato (Wheeler et al. 2019). Therefore, we conclude that the symptomatology of a given host is the result of the interaction between host plant species or genotypes and specific $V$. dahliae lineages, although future experiments should address this.

In this study, asymptomatic hosts included a wide variety of common weeds such as wild mustard species (Brassicaceae); species in the Solanaceae, Boraginaceae, Amaranthaceae, and Malvaceae families; and crops frequently grown in rotation with potato such as oat and sorghum. This is a relevant finding because oat and sorghum are intentionally rotated with potato for the management of Verticillium wilt. The strategy for rotating susceptible crops with ostensibly resistant species or fallow periods is to minimize inoculum build-up in soil by separating in time inoculum-production cycles in susceptible crops. However, an important question raised here is whether or not inoculum is produced on asymptomatic hosts infected with $V$. dahliae and whether this inoculum is effective on susceptible crops. Previous research found $V$. dahliae infecting a variety of host plants (mustards, millet, wheat, corn, sunflower, buckwheat, and barley) in the field without causing symptoms (Demirci and Genc 2009, 2011; Vallad et al. 2006; Wheeler and Johnson 2016; Wheeler et al. 2019). Some studies also showed that, in general, asymptomatic $V$. dahliae-infected rotational crops and weeds produced lower levels of V. dahliae inoculum (potentially microsclerotia) compared with infected potato under greenhouse conditions (Frederick et al. 2017; Wheeler and Johnson 2016). Additionally, other studies reported that $V$. dahliae can produce microsclerotia in plant roots even in the absence of systemic infections (Busch et al. 1978; Harrison and Isaac 1969; Lacy and Horner 1966; Mol 1995). If lineage 4B individuals infecting asymptomatic plants produce microsclerotia on roots and aboveground plant tissue, crop rotations may have the unintended effect of carrying over certain lineages between growing seasons and, thus, contributing inoculum to soil, resulting in inefficacious management. We speculate that $V$. dahliae multiplies during wilt epidemics on potato tissue but only a fraction of the lineage diversity is maintained through rotations by endophytic infections or colonization of nonhost roots because only lineage 4B infects asymptomatic hosts. A similar process could be occurring with other $V$. dahliae lineages, as suggested by the experiments previously mentioned (Frederick et al. 2017; Wheeler and Johnson 2016; Wheeler et al. 2019). Wheeler and Johnson (2016) sampled oat crops from two commercial fields with a history of Verticillium wilt of potato or mint in the Columbia Basin of central Washington but failed to isolate V. dahliae from oat stems. It is hard to explain the discrepancy in outcomes from Wheeler and Johnson (2016) and this study without speculation; however, one plausible explanation is that it is a consequence of differences in lineage composition of $V$. dahliae populations in the fields sampled.

Fig. 3. Minimum spanning network of Verticillium dahliae lineage 4B isolates from Pennsylvania and Israel. Analyses were performed using 1,343 singlenucleotide polymorphisms and 98 individuals. A, Populations are defined by genetic clusters identified by k-means and Bayesian Information Criterion (BIC). B, Populations are defined by host symptomatology. Isolates from asymptomatic hosts were genetically highly similar to isolates from symptomatic hosts and grouped in the same genetic cluster. 
$V$. dahliae populations causing Verticillium wilt of mint overwhelmingly comprise members of VCG2B, and populations causing Verticillium wilt of potato in Washington are mainly in VCG4A (Dung et al. 2013). As seen from our results, the lineage associated with asymptomatic infections in Israel and Pennsylvania is VCG4B. Therefore, the capability of establishing an endophytic interaction with a given asymptomatic host seems to be lineage dependent. These scenarios might explain the mixed outcomes provided by crop rotations in Verticillium wilt management (Busch et al. 1978; Davis et al. 1996, 1999a,b; Joaquim et al. 1988; Larkin

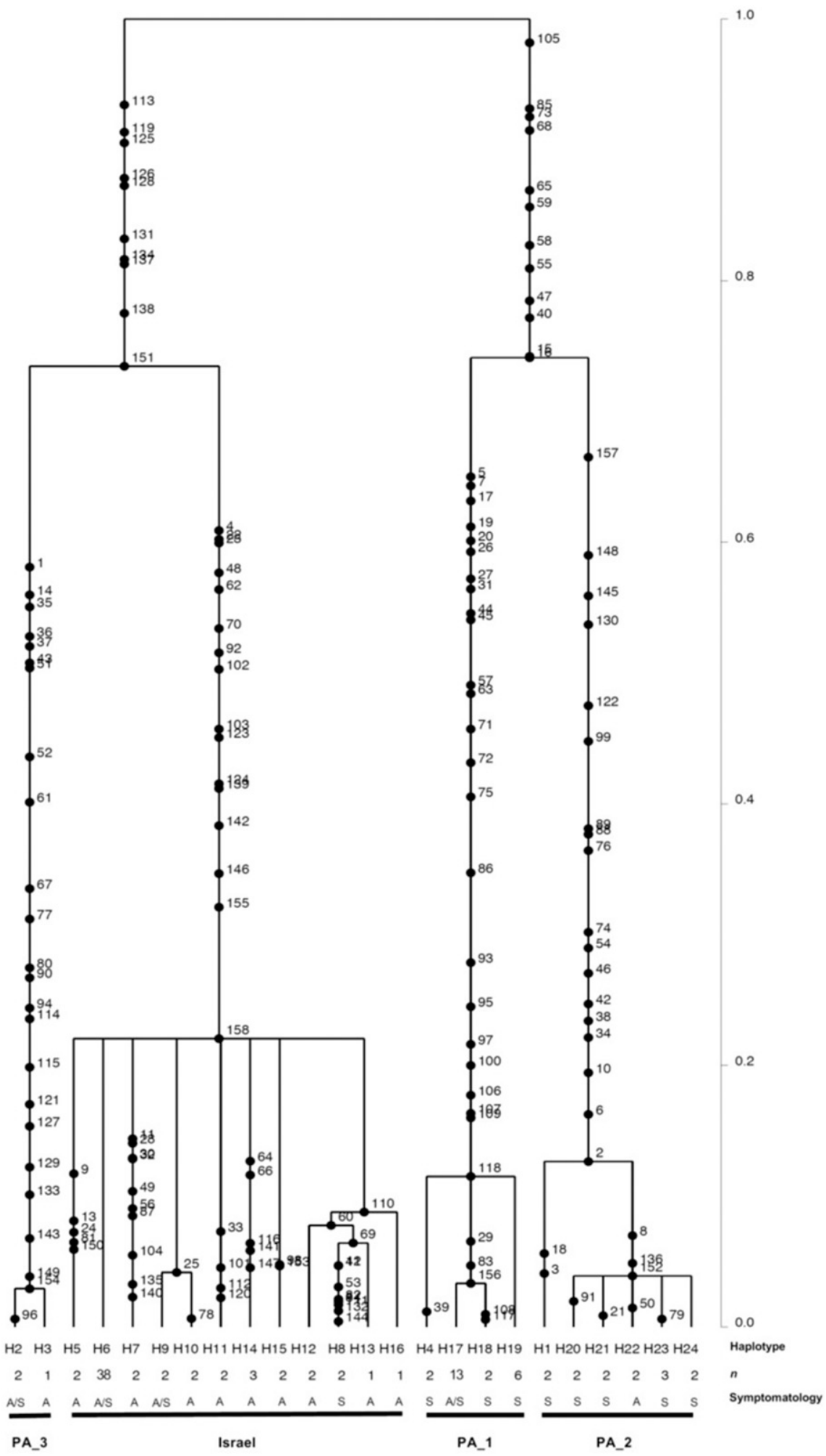

Fig. 4. Inferred coalescent genealogy of Verticillium dahliae lineage 4B using 158 single nucleotide polymorphisms (SNPs) among 98 isolates from Pennsylvania and Israel. Black dots represent nucleotide mutations and numbers beside them are their positions in the SNP sequence alignment. The scale on the right shows coalescent time rescaled to 1 . Haplotypes defined by Genetree (Haplotype), the number of isolates in each haplotype (n), host symptomatology of isolates in each haplotype (Symptomatology: A = asymptomatic and S = symptomatic), and the lineage-4B genetic clusters (Israel, PA_1, PA_2, and PA_3) are indicated below the tree. 
et al. 2011). Consequently, the fact that asymptomatic hosts can be carriers of lineage 4B between seasons should be considered during the management decision-making process.

The lineages identified in this study were differentiated by host of origin. For example, lineages $2 \mathrm{~A}$ and $2 \mathrm{~B}$ were found only in symptomatic hosts and lineage $4 \mathrm{~A}$ was found only in potato. Isolates from Pennsylvania in lineage $4 \mathrm{~B}$ were divided into three distinct groups whereas $4 \mathrm{~B}$ isolates from Israel grouped into a single cluster. A small group of Pennsylvanian 4B potato and oat isolates (PA_3) was genetically and evolutionarily more similar to the Israeli $4 \mathrm{~B}$ group than to the other Pennsylvanian 4B samples, and the coalescent genealogy showed that these two groups coalesced before the rest of the samples from Pennsylvania. The coalescent analysis also indicated that all of the lineage 4B haplotypes in Israel appear to be derived from one introduction or multiple introductions from the same clonal source population. Historically, Israel has imported potato seed tubers from northern European countries. Surveys of Israeli potato seed carried out from 1995 to 1998 found significant levels of infection with major seedborne pathogens, and more than one-third of the domestic certified seed tubers infested or infected by $V$. dahliae (Tsror et al. 1999). However, in a survey done in 2000 to 2005, 21 of 178 seed lots imported from northern Europe carried V. dahliae and all isolates belonged to lineage 4B (L. Tsror (Lahkim), unpublished results). Because potato seed trade between Israel and northern Europe happens annually, it is probable that lineage 4B was introduced into Israel on potato seed tubers through this commercial route. Studies on Colletotrichum coccodes, another common tuberborne potato pathogen, in Israel showed that imported certified seed tubers from Europe were infected with specific VCGs of the pathogen, making it possible to identify the sources of the introductions: VCG6 originated from The Netherlands and VCG7 from Scotland (Shcolnick et al. 2007). However, we cannot rule out the hypothesis that $V$. dahliae lineage 4B was introduced with hosts other than potato because this lineage has a broad host range. One plausible explanation for the relation between 4B populations in Israel and one small cluster of 4B isolates in Pennsylvania could be that they are descendants from the same source population located somewhere else and they were introduced with agricultural commodities. A comparison of lineage 4B isolates from a broader geographical sampling and a larger SNP dataset could help clarify migration routes of this lineage.

We did not find new lineages or lineages associated only with asymptomatic reservoirs as previously hypothesized and described in other host-pathogen systems (Bartoli et al. 2015; Monteil et al. 2013). The cropping history of a field is an important factor that may influence the diversity of $V$. dahliae lineages present in that field (Cohen et al. 2012). It is possible that the cropping history of the fields sampled in this study may have influenced the prevalence of lineage 4B infecting asymptomatic and symptomatic hosts. For example, lineage $1 \mathrm{~A}$, a lineage highly aggressive toward cotton and olive, was prevalent in areas of southern Spain with a long history of cultivation of these crops; however, a higher lineage diversity was found in provinces with a more diverse cropping history that had been more recently planted to olive (Jiménez-Díaz et al. 2011). In many regions of Israel, lineages other than 4B were more common in crops such as cotton and tomato until 15 years ago (L. Tsror (Lahkim), unpublished results). However, Verticillium wilt incidence in these crops was significantly reduced due to a decrease in cotton-growing area and the introduction of Verticillium wiltresistant varieties. As a consequence, potato and rotational crops, including orchards cultivated on fields with a history of potato cultivation, became the primary crops that harbor $V$. dahliae. Therefore, we speculate that $V$. dahliae lineage $4 \mathrm{~B}$, which is highly prevalent on potato, became the major lineage that can infect both symptomatic and asymptomatic hosts in Israel.

Although there was no significant differentiation of lineage $4 B$ isolates between populations from symptomatic and asymptomatic hosts (as illustrated in the MSN and the coalescent analysis) (Figs. 2 and 3 ), the pathogenicity of isolates recovered from asymptomatic hosts toward potato or other economically important crops still needs to be determined. However, overall, our study shows that asymptomatic rotational crops and weeds have the potential to be reservoirs of $V$. dahliae lineage $4 \mathrm{~B}$, which contains isolates pathogenic to potato and other economically important cultivated species. This may explain the lack of consistency in Verticillium wilt management provided by crop rotations, as discussed above. However, several additional research questions need to be addressed before augmenting current management recommendations. These include (i) how much inoculum is produced on asymptomatic hosts under field conditions; (ii) how crop cultural practices affect production, survival, viability, and genetic diversity of the inoculum; and (iii) how asymptomatic infections affect the dynamics of subsequent epidemics on susceptible hosts. Our study also highlights how little we know about the ecology of $V$. dahliae outside crop production. For instance, it is unknown what roles, if any, this fungus might play outside of agricultural systems; if plant pathogenicity is the main ecological role of the species or just an artifact of agriculture; and what conditions determine whether $V$. dahliae infections result in endophytic or pathogenic interactions. Knowing the range and nature of hosts and lineage diversity in a field is crucial for improving disease management because different $V$. dahliae lineages are associated with meaningful biological attributes such as pathogenicity, aggressiveness, and host range (Iglesias-Garcia et al. 2013; Jiménez-Díaz et al. 2006, 2016; Joaquim and Rowe 1991; Rafiei et al. 2018). To make agroecosystems more resilient and design more efficient and

TABLE 2. Analysis of molecular variance between Verticillium dahliae lineage 4B populations from symptomatic (Symp) and asymptomatic (Asymp) hosts collected from potato fields in Pennsylvania (PA) and Israel ${ }^{\mathrm{a}}$

\begin{tabular}{lccccccccc}
\hline Sample $^{\mathrm{b}}$ & Symp & Asymp & $\Phi^{\mathrm{c}}$ & $P$ value & Source of variation $^{\mathrm{d}}$ & df & Sum of squares & Variance components & Variation $(\%)^{2}$ \\
\hline Lineage 4B & 49 & 49 & 0.1405 & 0.001 & Between & 1 & $2,069.63$ & 37.54 \\
& $\ldots$ & $\ldots$ & $\ldots$ & $\ldots$ & Within & 96 & $22,096.00$ & 230.17 \\
Clusters $^{\mathrm{e}}$ & $\ldots$ & $\ldots$ & $\ldots$ & $\ldots$ & Total & 97 & $24,165.63$ & 267.71 \\
Israel & 19 & 40 & 0.0062 & 0.165 & $\ldots 5.95$ & 105 \\
PA_1 & 18 & 5 & 0.0449 & 0.159 & $\ldots$ & $\ldots$ & $\ldots$ & $\ldots$ & $\ldots$ \\
PA_2 & 11 & 2 & 0.1403 & 0.112 & $\ldots$ & $\ldots$ & $\ldots$ & $\ldots$ & $\ldots$ \\
\hline
\end{tabular}

a Data were permuted 999 times.

${ }^{\mathrm{b}}$ In the sample analyzed, isolates were grouped in populations defined by symptomatology of the host they were isolated from: symptomatic (isolates recovered from symptomatic hosts) and asymptomatic (isolates recovered from asymptomatic hosts).

c Population differentiation statistic $(\Phi)$ analogous to fixation index $\left(F_{\mathrm{ST}}\right)$ (Excoffier et al. 1992).

${ }^{\mathrm{d}}$ Between populations, within population, and total.

e Genetic clusters within lineage 4B. Isolates were assigned to genetic clusters identified by k-means and Bayesian Information Criterion (BIC) based on single nucleotide polymorphism data. Level of genetic differentiation between $V$. dahliae isolates from cluster PA_3 was not estimated because of the small sample size $(n=3)$. 
sustainable management practices against Verticillium wilts, we should take into account the lineage diversity and ecology of V. dahliae populations.

\section{ACKNOWLEDGMENTS}

We thank M. Mansfield, L. Gur, and F. Abu Moch for their technical support; N. Korolev for her valuable advice and collection; and growers in Pennsylvania and Israel for allowing us to sample in their fields. All of the files with SNP data used for the analyses in this study can be accessed at GitHub (https://github.com/laurabau/BautistaJalon_Vdahliae).

\section{LITERATURE CITED}

Atallah, Z. A., Maruthachalam, K., du Toit, L., Koike, S. T., Davis, R. M., Klosterman, S. J., Hayes, R. J., and Subbarao, K. V. 2010. Population analyses of the vascular plant pathogen Verticillium dahliae detect recombination and transcontinental gene flow. Fungal Genet. Biol. 47:416-422.

Bacon, C. W., and Hinton, D. M. 1996. Symptomless endophytic colonization of maize by Fusarium moniliforme. Can. J. Bot. 74:1195-1202.

Bahlo, M., and Griffiths, R. C. 2000. Inference from gene trees in a subdivided population. Theor. Popul. Biol. 57:79-95.

Bartoli, C., Lamichhane, J. R., Berge, O., Guilbaud, C., Varvaro, L., Balestra, G. M., Vinatzer, B. A., and Morris, C. E. 2015. A framework to gauge the epidemic potential of plant pathogens in environmental reservoirs: The example of kiwifruit canker. Mol. Plant Pathol. 16:137-149.

Berbegal, M., Ortega, A., Jiménez-Gasco, M. M., Olivares-García, C., Jiménez-Díaz, R. M., and Armengol, J. 2010. Genetic diversity and host range of Verticillium dahliae isolates from artichoke and other vegetable crops in Spain. Plant Dis. 94:396-404.

Bhat, R. G., Smith, R. F., Koike, S. T., Wu, B. M., and Subbarao, K. V. 2003. Characterization of Verticillium dahliae isolates and wilt epidemics of pepper. Plant Dis. 87:789-797.

Bradbury, P. J., Zhang, Z., Kroon, D. E., Casstevens, T. M., Ramdoss, Y., and Buckler, E. S. 2007. TASSEL: Software for association mapping of complex traits in diverse samples. Bioinformatics 23:2633-2635.

Burdon, J. J. 1991. Fungal pathogens as selective forces in plant populations and communities. Aust. J. Ecol. 16:423-432.

Burdon, J. J., Thrall, P. H., and Ericson, L. 2006. The current and future dynamics of disease in plant communities. Annu. Rev. Phytopathol. 44:19-39.

Busch, L. V., Smith, E. A., and Njohelango, F. 1978. Effect of weeds on value of rotation as a practical control for Verticillium wilt of potato. Can. Plant Dis. Surv. 58:61-64

Chandelier, A., Laurent, F., Dantinne, D., Mariage, L., Etienne, M., and Cavelier, M. 2003. Genetic and molecular characterization of Verticillium dahliae isolates from woody ornamentals in Belgian nurseries. Eur. J. Plant Pathol. 109:943-952.

Chessel, D., Dufour, A., and Thioulouse, J. 2004. The ade4 Package-I: Onetable methods. R News 4:5-10.

Cohen, Y., Goldstein, E., Hetzroni, A., Lensky, I., Zig, U., and Tsror (Lahkim), L. 2012. Knowledge-based prediction model of Verticillium wilt on potato and its use for rational crop rotation. Comput. Electron. Agric. 85:112-122.

Davis, J. R., and Huisman, O. C. 2004. Comments on the feature "Potato early dying: Management challenges in a changing production environment". Plant Dis. 88:1168-1171.

Davis, J. R., Huisman, O. C., Everson, D. O., Schneider, A. T., and Sorensen, L. H. 1999a. Addendum. Am. J. Potato Res. 76:254.

Davis, J. R., Huisman, O. C., Everson, D. O., Sorensen, L. H., and Schneider, A. T. 1999b. Control of Verticillium wilt of the Russet Burbank potato with corn and barley. Am. J. Potato Res. 76:367.

Davis, J. R., Huisman, O. C., Westermann, D. T., Hafez, S. L., Everson, D. O., Sorensen, L. H., and Schneider, A. T. 1996. Effects of green manures on Verticillium wilt of potato. Phytopathology 86:444-453.

Demers, J. E., Gugino, B. K., and Jiménez-Gasco, M. M. 2015. Highly diverse endophytic and soil Fusarium oxysporum populations associated with fieldgrown tomato plants. Appl. Environ. Microbiol. 81:81-90.

Demirci, E., and Genc, T. 2009. Vegetative compatibility groups of Verticillium dahliae isolates from weeds in potato fields. J. Plant Pathol. 91:671-676.

Demirci, E., and Genc, T. 2011. Vegetative compatibility groups of Verticillium dahliae isolates from weeds in potato fields [Correction]. J. Plant Pathol. 93:757.

Dung, J. K. S., Peever, T. L., and Johnson, D. A. 2013. Verticillium dahliae populations from mint and potato are genetically divergent with predominant haplotypes. Phytopathology 103:445-459.

Edel, V., Steinberg, C., Gautheron, N., and Alabouvette, C. 1997. Populations of nonpathogenic Fusarium oxysporum associated with roots of four plant species compared to soilborne populations. Phytopathology 87:693-697.
Elshire, R. J., Glaubitz, J. C., Sun, Q., Poland, J. A., Kawamoto, K., Buckler, E. S., and Mitchell, S. E. 2011. A robust, simple genotyping-by-sequencing (GBS) approach for high diversity species. PLoS One 6:e19379.

Evans, G. 1971. Influence of weed hosts on the ecology of Verticillium dahliae in newly cultivated areas of the Namoi Valley, New South Wales. Ann. Appl. Biol. 67:169-175.

Evans, G., and Gleeson, A. C. 1973. Observations on the origin and nature of Verticillium dahliae colonizing plant roots. Aust. J. Biol. Sci. 26:151-161.

Excoffier, L., Smouse, P. E., and Quattro, J. M. 1992. Analysis of molecular variance inferred from metric distances among DNA haplotypes: Application to human mitochondrial DNA restriction data. Genetics 131:479-491.

Frederick, Z. A., Cummings, T. F., and Johnson, D. A. 2017. Susceptibility of weedy hosts from Pacific Northwest potato production systems to cropaggressive isolates of Verticillium dahliae. Plant Dis. 101:1500-1506.

Garrison, E., and Marth, G. 2012. Haplotype-based variant detection from short-read sequencing. arXiv:1207.3907 [q-bio.GN]. https://arxiv.org/abs/ 1207.3907

Gilbert, G. S. 2002. Evolutionary ecology of plant diseases in natural ecosystems. Annu. Rev. Phytopathol. 40:13-43.

Grünwald, N. J., McDonald, B. A., and Milgroom, M. G. 2016. Population genomics of fungal and oomycete pathogens. Annu. Rev. Phytopathol. 54: 323-346.

Harrison, J. A. C., and Isaac, I. 1969. Survival of the causal agents of 'early dying disease' (Verticillium wilt) of potatoes. Ann. Appl. Biol. 63:277-288.

Iglesias-Garcia, A. M., Villarroel-Zeballos, M. I., Feng, C., du Toit, L. J., and Correll, J. C. 2013. Pathogenicity, virulence, and vegetative compatibility grouping of Verticillium isolates from spinach seed. Plant Dis. 97: 1457-1469.

Jiménez-Díaz, R. M., Cirulli, M., Bubici, G., Jiménez-Gasco, M. M., Antoniou, P. P., and Tjamos, E. C. 2012. Verticillium wilt, a major threat to olive production: Current status and future prospects for its management. Plant Dis. 96:304-329.

Jiménez-Díaz, R. M., Mercado-Blanco, J., Olivares-García, C., Collado-Romero, M., Bejarano-Alcázar, J., Rodríguez-Jurado, D., Giménez-Jaime, A., García-Jiménez, J., and Armengol, J. 2006. Genetic and virulence diversity in Verticillium dahliae populations infecting artichoke in eastern-central Spain. Phytopathology 96:288-298.

Jiménez-Díaz, R. M., Olivares-García, C., Landa, B. B., Jiménez-Gasco, M. M., and Navas-Cortés, J. A. 2011. Region-wide analysis of genetic diversity in Verticillium dahliae populations infecting olive in Andalusia and agricultural factors influencing the distribution and prevalence of vegetative compatibility groups and pathotypes. Phytopathology 101: 304-315.

Jiménez-Díaz, R. M., Olivares-García, C., Trapero-Casas, J. L., Jiménez-Gasco, M. M., Navas-Cortés, J. A., Landa, B. B., and Milgroom, M. G. 2016. Variation of pathotypes and races and their correlations with clonal lineages in Verticillium dahliae. Plant Pathol. 66:651-666.

Joaquim, T. R., and Rowe, R. C. 1991. Vegetative compatibility and virulence of strains of Verticillium dahliae from soil and potato plants. Phytopathology 81:552-558.

Joaquim, T. R., Smith, V. L., and Rowe, R. C. 1988. Seasonal variation and effects of wheat rotation on populations of Verticillium dahliae Kleb. in Ohio potato field soils. Am. Potato J. 65:439-447.

Jombart, T. 2008. adegenet: A R package for the multivariate analysis of genetic markers. Bioinformatics 24:1403-1405.

Jombart, T., Devillard, S., and Balloux, F. 2010. Discriminant analysis of principal components: A new method for the analysis of genetically structured populations. BMC Genet. 11:94.

Kamvar, Z. N., Tabima, J. F., and Grünwald, N. J. 2014. poppr: An R package for genetic analysis of populations with clonal, partially clonal, and/or sexual reproduction. PeerJ 2:e281.

Klosterman, S. J., Subbarao, K. V., Kang, S., Veronese, P., Gold, S. E., Thomma, B. P. H. J., Chen, Z., Henrissat, B., Lee, Y. H., Park, J., Garcia-Pedrajas, M. D., Barbara, D. J., Anchieta, A., de Jonge, R., Santhanam, P., Maruthachalam, K., Atallah, Z., Amyotte, S. G., Paz, Z., Inderbitzin, P., Hayes, R. J., Heiman, D. I., Young, S., Zeng, Q., Engels, R., Galagan, J., Cuomo, C. A., Dobinson, K. F., and Ma, L. J. 2011. Comparative genomics yields insights into niche adaptation of plant vascular wilt pathogens. PLoS Pathog 7:e1002137.

Korolev, N., Katan, J., and Katan, T. 2000. Vegetative compatibility groups of Verticillium dahliae in Israel: Their distribution and association with pathogenicity. Phytopathology 90:529-536.

Korolev, N., Pérez-Artés, E., Bejarano-Alcázar, J., Rodríguez-Jurado, D., Katan, J., Katan, T., and Jiménez-Díaz, R. M. 2001. Comparative study of genetic diversity and pathogenicity among populations of Verticillium dahliae from cotton in Spain and Israel. Eur. J. Plant Pathol. 107:443-456.

Korolev, N., Perez-Artés, E., Mercado-Blanco, J., Bejarano-Alcázar, J., Rodríguez-Jurado, D., Jiménez-Díaz, R. M., Katan, T., and Katan, J. 2008. Vegetative compatibility of cotton-defoliating Verticillium dahliae in Israel 
and its pathogenicity to various crop plants. Eur. J. Plant Pathol. 122: 603-617.

Krikun, J., and Bernier, C. C. 1987. Infection of several crop species by two isolates of Verticillium dahliae. Can. J. Plant Pathol. 9:241-245.

Krikun, J., and Bernier, C. C. 1990. Morphology of microsclerotia of Verticillium dahliae in roots of gramineous plants. Can. J. Plant Pathol. 12: 439-441.

Kumar, S., Stecher, G., and Tamura, K. 2016. MEGA7: Molecular evolutionary genetics analysis version 7.0 for bigger datasets. Mol. Biol. Evol. 33:1870-1874

Lacy, M. L., and Horner, C. E. 1966. Behaviour of Verticillium dahliae in the rhizosphere and on roots of plants susceptible, resistant, and immune to wilt. Phytopathology 56:427-430.

Larkin, R. P., Honeycutt, C. W., and Olanya, O. M. 2011. Management of Verticillium wilt of potato with disease-suppressive green manures and as affected by previous cropping history. Plant Dis. 95:568-576.

Levy, J., and Isaac, I. 1976. Colonization of host tissue of varying resistance to Verticillium dahliae. Trans. Br. Mycol. Soc. 67:91-94.

Li, H. 2013. Aligning sequence reads, clone sequences and assembly contigs with BWA-MEM. arXiv:1303.3997 [q-bio.GN]. https://arxiv.org/abs/ 1303.3997

Li, H., Handsaker, B., Wysoker, A., Fennell, T., Ruan, J., Homer, N., Marth, G., Abecasis, G., and Durbin, R. 2009. The Sequence alignment/map (SAM) format and SAMtools. Bioinformatics 25:2078-2079.

Lofgren, L. A., LeBlanc, N. R., Certano, A. K., Nachtigall, J., LaBine, K. M., Riddle, J., Broz, K., Dong, Y., Bethan, B., Kafer, C. W., and Kistler, H. C. 2018. Fusarium graminearum: Pathogen or endophyte of North American grasses? New Phytol. 217:1203-1212.

Malcolm, G. M., Kuldau, G. A., Gugino, B. K., and Jiménez-Gasco, M. M. 2013. Hidden host plant associations of soilborne fungal pathogens: An ecological perspective. Phytopathology 103:538-544.

Martin, D. P., Murrell, B., Golden, M., Khoosal, A., and Muhire, B. 2015. RDP4: Detection and analysis of recombination patterns in virus genomes. Virus Evol. 1:vev003.

Milgroom, M. G., Jiménez-Gasco, M. M., Olivares-García, C., Drott, M. T., and Jiménez-Díaz, R. M. 2014. Recombination between clonal lineages of the asexual fungus Verticillium dahliae detected by genotyping by sequencing. PLoS One 9:e106740.

Milgroom, M. G., Jiménez-Gasco, M. M., Olivares-García, C., and Jiménez-Díaz, R. M. 2016. Clonal expansion and migration of a highly virulent, defoliating lineage of Verticillium dahliae. Phytopathology 106:1038-1046.

Mol, L. 1995. Formation of microsclerotia of Verticillium dahliae on different crops and potato cultivars. Neth. J. Agric. Sci. 43:205-215.

Monacell, J. T., and Carbone, I. 2014. Mobyle SNAP Workbench: A webbased analysis portal for population genetics and evolutionary genomics. Bioinformatics 30:1488-1490.

Monteil, C. L., Cai, R., Liu, H., Llontop, M. E., Leman, S., Studholme, D. J., Morris, C. E., and Vinatzer, B. A. 2013. Nonagricultural reservoirs contribute to emergence and evolution of Pseudomonas syringae crop pathogens. New Phytol. 199:800-811.

Monteil, C. L., Yahara, K., Studholme, D. J., Mageiros, L., Méric, G., Swingle, B., Morris, C. E., Vinatzer, B. A., and Sheppard, S. K. 2016. Populationgenomic insights into emergence, crop adaptation and dissemination of Pseudomonas syringae pathogens. Microb. Genomics 2:e000089.

Pegg, G. F., and Brady, B. L. 2002. Verticillium Wilts. CABI Publishing, Wallingford, U.K. doi.org/10.1079/9780851995298.0000
Rafiei, V., Banihashemi, Z., Bautista-Jalon, L. S., Jiménez-Gasco, M. M., Turgeon, B. G., and Milgroom, M. G. 2018. Population genetics of Verticillium dahliae in Iran based on microsatellite and single nucleotide polymorphism markers. Phytopathology 108:780-788.

R Core Team. 2020. R: A Language and Environment for Statistical Computing. R Foundation for Statistical Computing, Vienna, Austria. https:// www.R-project.org/

Rowe, R. C., Davis, J. R., Powelson, M. L., and Rouse, D. I. 1987. Potato early dying: Causal agents and management strategies. Plant Dis. 71:482-489.

Rowe, R. C., and Powelson, M. L. 2002. Potato early dying: Management challenges in a changing production environment. Plant Dis. 86:1184-1193.

Schnathorst, W. C., and Mathre, D. E. 1966. Host range and differentiation of a severe form of Verticillium albo-atrum in cotton. Phytopathology 56:1155-1161.

Shcolnick S., Dinoor, A. and Tsror (Lahkim), L. 2007. Additional vegetative compatibility groups in Colletotrichum coccodes subpopulations from Europe and Israel. Plant Dis. 91:805-808.

Stergiopoulos, I., and Gordon, T. R. 2014. Cryptic fungal infections: The hidden agenda of plant pathogens. Front. Plant Sci. 5:506.

Suproniene, S., Kadziene, G., Irzykowski, W., Sneideris, D., Ivanauskas, A., Sakalauskas, S., Serbiak, P., Svegzda, P., Kelpsiene, J., Pranaitiene, S., and Jedryczka, M. 2019. Asymptomatic weeds are frequently colonised by pathogenic species of Fusarium in cereal-based crop rotations. Weed Res. 59:312-323.

Tarasov, A., Vilella, A. J., Cuppen, E., Nijman, I. J., and Prins, P. 2015. Sambamba: Fast processing of NGS alignment formats. Bioinformatics 31 : 2032-2034.

Tsror, L., Aharon, M., and Erlich, O. 1999. Survey of bacterial and fungal seedborne diseases in imported and domestic potato seed tubers. Phytoparasitica 27:215-226

Tsror (Lahkim), L., Hazanovsky, M., Mordechi-Lebiush, S., and Sivan, S. 2001. Aggressiveness of Verticillium dahliae isolates from different vegetative compatibility groups to potato and tomato. Plant Pathol. 50:477-482.

Tsror (Lahkim), L., and Levin, A. G. 2003. Vegetative compatibility and pathogenicity of Verticillium dahliae Kleb. isolates from olive in Israel. J. Phytopathol. 151:451-455.

Tsror (Lahkim), L., Shapira, R.., Erlich, O., Hazanovsky, M., and Lebiush, S. 2020. Characterization of weeds and rotational crops as alternative hosts of Spongospora subterranea, the causal agent of powdery scab in Israel. Plant Pathol. 69:294-301

Tsror (Lahkim), L., Shlevin, E., and Peretz-Alon, I. 2005. Efficacy of metam sodium for controlling Verticillium dahliae prior to potato production in sandy soils. Am. J. Potato Res. 82:419-423.

Vallad, G. E., Qin, Q. M., Grube, R. C., Hayes, R. J., and Subbarao, K. V. 2006. Characterization of race-specific interaction among isolates of Verticillium dahliae pathogenic on lettuce. Phytopathology 96:1380-1387.

Wang, B., Brubaker, C. L., Summerell, B. A., Thrall, P. H., and Burdon, J. J. 2010. Local origin of two vegetative compatibility groups of Fusarium oxysporum f. sp. vasinfectum in Australia. Evol. Appl. 3:505-524.

Wheeler, D. L., Dung, J. K. S., and Johnson, D. A. 2019. From pathogen to endophyte: An endophytic population of Verticillium dahliae evolved from a sympatric pathogenic population. New Phytol. 222:497-510.

Wheeler, D. L., and Johnson, D. A. 2016. Verticillium dahliae infects, alters plant biomass, and produces inoculum on rotation crops. Phytopathology 106:602-613.

Xin, X., Kvitko, B., and He, S. Y. 2018. Pseudomonas syringae: What it takes to be a pathogen. Nat. Rev. Microbiol. 16:316-328. 